\title{
Miscellany
}

\section{Caring fund established for the support of families with CJD}

The CJD Support Network, the leading care organisation for families affected by all forms of CJD, has set up a caring fund for the relief of families in financial crisis. The fund, established by charitable donations, will make small one off grants to help with caring expenses, respite care and to pay for funeral costs. They also run a national helpline on 01630673973 . For more information, contact Clive Evers on 0171306 0837. Gillian Turner on 01630673973 or Veronica Fuller on 01713060813.

\section{National Alzheimer's helpline launched}

A national helpline has been set up by the Alzheimer's Disease Society for carers, health care professionals and people with dementia to get up-to-date specialist help, support and advice about Alzheimer's disease and other forms of dementia. The helpline is open from Monday to Friday, 8 a.m. to $6 \mathrm{p.m}$. and the number to ring is 08453000336 . Calls are charged at local rate. For more information, contact Veronica Fuller on 01713060813.

\section{New Publications}

World Health Organization Publications have just published the second edition of Application of the International Classification of Diseases to Neurology (ICD-NA). This second edition has been revised to reflect current clinical concepts in the neurosciences as well as the new coding system introduced with ICD-10. Further infor- mation: The Stationery Office Publications Centre, 51 Nine Elms Lane, London SW8 5DR (Telephone: 0171873 9090; Fax: 0171873 8200; e-mail: book.enquiries@theso.co.uk).

Amsterdam University Press have recently published two new books. Euthanasia and Law in the Netherlands by John Griffiths, Alex Bood and Heleen Weyers is about euthanasia and other medical practices that shorten life, and about their legal regulation. The central focus is on Dutch law and the moral and legal principles that have played a part in the Dutch debate. From Shell Shock to Combat Stress: A Comparative History of Military Psychiatry by Hans Binneveld presents a history of the field of military psychiatry. The first part provides a historical survey of the conduct of war with an emphasis on front-line experiences and psychological pressures. The second part deals with military psychiatry itself. Further information: Rita Snaddon or Françoise Kraaijenzank at Amsterdam University Press (Telephone: 0031 20420 0050; Fax: 003120420 3124; e-mail: aup@aup.uva.nl).

Rebuilding Therapy: Overcoming the Past for a More Effective Future by Michael Gass is a new publication from Praeger Publications. In the first book to be written on this reconstructive therapy, Gass details its theoretical foundations, methodology and approaches to acquaint mental health and related professionals with its value on a short- and long-term basis. Further information: Praeger Publishers, 3 Henrietta Street. London WC2E 8LU (Telephone: 0171240 0856; Fax: 0171379 0609). 